\title{
O Direito Penal do inimigo: uma análise acerca do expansionismo penal no Estado Democrático de Direito
}

\author{
The Enemy's Criminal Law: an analysis about Criminal \\ Expansionism in the Democratic State of Law
}

Edson Vieira da Silva Filho ${ }^{1}$

Bibiana de Paiva Terra ${ }^{2}$

\begin{abstract}
RESUMO
O presente artigo compõe uma análise teórica acerca da expansão do direito penal no Estado Democrático de Direito. A Constituição Federal Brasileira de 1988 prevê um direito penal garantista, assentado na mínima intervenção e nos direitos humanos. No entanto, as sociedades modernas vem cada vez mais sofrendo com a cultura do punitivismo. O surgimento de novas condutas ilícitas, a criação de novos tipos penais, o recrudescimento de penas e dos tipos penais já existentes são apenas algumas das condutas adotadas pelo Estado. Essa situação acabou por gerar um aumento da utilização do direito penal em seu viés maximalista, o que, por sua vez, acabou gerando o fenômeno conhecido como expansionismo penal. Dele resultou uma vertente ainda mais radical, conhecida como direito penal do inimigo, que tem como seu principal representante Günter Jakobs. No entanto, esses são incompatíveis com o constitucionalismo contemporâneo brasileiro. Sendo assim, através da metodologia da revisão bibliográfica, o objetivo geral da pesquisa, bem como sua própria conclusão, pretende provocar uma reflexão crítica dessas vertentes do direito penal, no sentido de tentar entender de que forma elas contribuem para o direito penal abandonar o minimalismo em busca de respostas eficientes para os anseios e inseguranças da sociedade contemporânea. Para tanto, compõem o referencial teórico da pesquisa Jesús-Maria Silva Sánchez, Eugenio Raúl Zaffaroni e Günter Jakobs.
\end{abstract}

\section{PALAVRAS-CHAVE}

Direito Penal; Expansionismo Penal; Direito Penal do Inimigo.

\footnotetext{
${ }^{1}$ Pós-Doutor pela UNISINOS, sob a orientação do Professor Doutor Lenio Luiz Streck. Doutor em Direito pela UNESA na linha Direitos Fundamentais e Novos Direitos. Mestre pela Universidade São Francisco (2002), mestre pela Universidade Federal do Paraná, UFPR. Graduado em Direito pela PUC Belo Horizonte -MG (1986). Delegado de Polícia Classe Geral, aposentado - Polícia Civil do Estado de Minas Gerais. Gestor do Núcleo de Atividades Complementares da Faculdade de Direito do Sul de Minas, Professor do Programa de Mestrado em Direito da Faculdade de Direito do Sul de Minas. Pesquisador-Líder do Grupo de Pesquisa do CNPq "Razão Crítica e Justiça Penal" (PPGD/FDSM).

${ }^{2}$ Mestranda em Direito, com ênfase em Constitucionalismo e Democracia, pela Faculdade de Direito do Sul de Minas. Graduada em Direito pela Pontifícia Universidade Católica de Minas Gerais - PUC Minas. Integrante dos grupos de pesquisa do CNPq "Direito Internacional Crítico" e "Razão Crítica e Justiça Penal”. Advogada.
} 


\begin{abstract}
The present paper compose a theoretical analysis of the expansion of criminal law in the Democratic State of Law. The 1988 Brazilian Federal Constitution provides for a guaranteed criminal law, allowed for minimal intervention and human rights. However, modern societis are increasingly suffering from the culture of punitivism. The emergence of nwe illicit conduct, the creation of new types of penalties that already exist are just some of the behaviors adopted by the State. This situation ended up generating an increase in the use of criminal law in maximum cases, or that, in turn, ended up generating or the history know as criminal expansion. This resulted in an even more radical aspect, know as the enemy's criminal law, whose main representative is Günter Jakobs. However, the are incompatible with contemporary brazilian constitucionalism. Therefore, through the bibliographic review methodology, the general objective of the research, as well as its own conclusion, can cause a critical reflection on legal issues, with no sense of trying to understand how they contribute to the abandoning of criminal law or minimalism in search for efficient answers for analysts and insurers of contemporary society. To do so, compose the reference Jesús-Maria Silva Sánchez, Eugenio Raúl Zaffaroni and Günter Jakobs.
\end{abstract}

\title{
KEYWORDS
}

Criminal Law; Criminal Expansionism; Criminal Law of the Enemy.

\section{INTRODUÇÃO}

As sociedades modernas, cada vez mais, vem sofrendo profundas influências da globalização, o que acaba por gerar reflexos na extensão dos direitos e nos modelos penais que deles protegem e que deles decorrem. O surgimento de novas condutas ilícitas, a criação de novos tipos penais, o recrudescimento de penas e dos tipos penais já existentes são apenas algumas das condutas adotadas por diversos Estados que se sentem encurralados pelas demandas midiáticas e sociais, que variam entre os ideais de promoção de liberdade e a demanda pela contenção de direitos. Essa situação acabou por incitar um aumento da utilização do direito penal, fenômeno que acabou ficando conhecido como "expansionismo penal" ${ }^{3}$ É a encruzilhada entre o(s) garantismo(s) minimalista(s) e o(s) exapansionismo(s) eficientintas(s).

\footnotetext{
${ }^{3}$ SILVA SÁNCHEZ, Jesús-María. A expansão do direito penal: aspectos da política criminal nas sociedades pós-industriais. Trad. Luiz Otávio de Oliveira Rocha. São Paulo: Revista dos Tribunais, 2013.
} 
Da opção pelo expansionismo Penal surge então um movimento emergencial, que dá lugar a um grande movimento de política criminal em que a aplicação da lei penal serve como resposta de urgência a segurança. No entanto, isso acarreta uma série de aumento de penas e medidas que relativizam direitos e garantias penais em nome da segurança social e da busca por soluções imediatas. ${ }^{4}$

Diante disso, busca-se demonstrar que o movimento do expansionismo penal está relacionado com a busca das sociedades modernas pela segurança a ser efetivada pelo aumento da ação das intâncias de controle penal/policial, como uma resposta preventiva ao que se convencionou chamar de sociedade de risco ${ }^{5}$, atribuído as sociedades contemporâneas ou pósmodernas. Isso ocorre porque as pessoas estão inseridas em um mundo que escapa do seu controle, onde o perigo, os riscos e a criminalidade são temas muito recorrentes no seu cotidiano e que devem ser contidos antes que se materializem como danos. ${ }^{6}$

É preciso lembrar que o risco é, por sua própria definição, o não evento e que eficiência não corresponde a violência desmedida. O direito penal só pode ser concebido como um conjunto de respostas a danos perpetrados contra bens jurídicos penais e a eficiência só se compõe por uma compreensão qualitativa, que envolve especialmente a produção de efeitos positivos no tocante a redução de conflitos e violências sociais na esfera penal, resultados que não tem se demonstrado estatisticamente. Ou seja, a prevenção do risco não tem se mostrado eficiente na contenção do dano e a pretensa eficiência nascida de um sistema máximo não tem trazido resultados satisfatórios na efetiva redução/controle dos delitos.

Além disso, como consequência desse maximalismo penal, o Estado, em uma dinâmica expansionista penal, faz surgir um lado mais radical do direito penal, que Jesús-Maria Silva Sánchez denomina de "direito penal de terceira velocidade". ${ }^{7}$ Esse é representado pela teoria

\footnotetext{
${ }^{4}$ BONACCORSI, Daniela Villani. Constitucionalismo e emergencialismo penal: progresso global e retrocesso democrático. Revista do instituto de hermenêutica jurídica - RIHJ, v. 11, n.13, p. 165-186, jan./jun. 2013.

${ }^{5}$ BECK, Ulrich. Sociedade de Risco: rumo a uma outra modernidade. Trad. Sebastião Nascimento. $2^{\text {a }}$ Ed. São Paulo: 34, 2011.

${ }^{6}$ SILVA, Marina Helena Vieira da. POSTERARO, Talita Piedade. Tolerância Zero. In: SILVA FILHO, Edson Vieira da (Org.). O Direito Penal e suas faces: Da modernidade ao Neoconstitucionalismo: Volume 2 - O Direito Penal visto de uma perspectiva maximalista. São Paulo: Lexia, 2013.

${ }^{7}$ SILVA SÁNCHEZ, Jesús-María. A expansão do direito penal: aspectos da política criminal nas sociedades pósindustriais. Trad. Luiz Otávio de Oliveira Rocha. São Paulo: Revista dos Tribunais, 2013.
} 
do direito penal do inimigo, do alemão Günter Jakobs, que separa os indivíduos entre bons cidadãos e inimigos do Estado.

Construída a partir de uma base contratualista, a teoria de Jakobs traz uma distinção entre os cidadãos e os considerados inimigos do Estado. $\mathrm{O}$ autor ressalta que é necessário a existência de duas espécies de direito penal. De um lado, o direito penal do cidadão - um direito destinado ao delinquente comum, em que suas garantias constitucionais e penais são obedecidas. Já do outro lado, o direito penal do inimigo - destinado àquele que se coloca contrário ao pacto social, onde as suas garantias penais constitucionais dão lugar a um direito cruel e penas desumanas ${ }^{8}$ - é o manequeísmo moderno.

Diante dessas concepções, o presente artigo se desenvolve a partir do problema central de que existe uma demanda legítma para a contenção da violência social. A partir disso, traz como hipótese que a contenção do risco e o maximalismo penal não atendem a tal demanda. E, com isso, tem como objetivo demonstrar que um direito penal constitucionalmente adequado pode dar respostas mais eficientes (diferenciando eficiencia de violência) e que só um resgate da legitimidade por uma perspectiva garantista e minimalista é o caminho para o controle social penal.

O ensaio foi construído através da metodologia da revisão bibliográfica, tendo sido feita uma investigação teórica dividida em três tópicos e que comporta uma análise crítica acerca do expansionismo penal no Estado Democrático de Direito. A escolha desse tema partiu da necessidade de se entender o fenômeno do expansionismo penal e quais os seus reflexos no Estado Democrático de Direito do Brasil contemporâneo. Foram utilizados como referênciais teóricos da pesquisa Eugenio Raúl Zaffaroni, para abordar o mininalismo penal; a seguir, SilvaSánchez, para retratar acerca da expansão do direito penal; e, por fim, Günter Jakobs, para trabalhar a teoria do direito penal do inimigo.

\footnotetext{
${ }^{8}$ JAKOBS, Günther; MELIÁ, Manuel Cancio. Direito penal do inimigo, noções e críticas. Tradução de André Luis Callegari e Nobreu José Giancomolli. 2 Ed. Cidade: Editora Livraria do Advogado. 2007.
} 


\section{O MAXimalismo PENAL E O FORTALECIMENTO DE PRÁticas REPRESSIVAS}

A sociedade moderna, direta ou indiretamente, tem influenciado o direito. A contemporaneidade, especialmente no período pós-industrial, trouxe para o âmbito do direito penal novas demandas, em razão da preocupação com os novos bens jurídicos e com a segurança (o ideal da vida moderna e do modelo de bem estar social). Além disso, faz surgir novas espécies de condutas delituosas, que vão das mais simples e de baixo impacto as mais complexas e preocupantes, como o crime organizado e o terrorismo, entre outros mais. Nesse contexto, nessas sociedades ditas modernas, o direito penal ganha novos rumos de discussão. ${ }^{9}$

Nesse sentido, partindo-se do pressuposto de uma sociedade moderna - que ainda ${ }^{10}$ se estrutura a partir de uma racionalidade liberal, individual e burguesa - se verifica o caráter máximo do direito penal, com o recrudescimento punitivo e a flexibilização das garantias penais e processuais penais. A partir disso pode ser visto um reforço da ideia do punitivismo e da utilização do direito Penal maximalista, que tem a violência associada à sua efetividade e é usado pelo Estado como meio de controle social. ${ }^{11}$

Diante desse cenário, com a propagação da cultura do punitivismo marcando por mais presença do Estado demonstrado a partir de respostas cada vez mais violentas (já que há uma tendência de associar a violência a eficiência) tomando cada vez mais espaço nas sociedades modernas, há um recrudescimento do direito penal e uma maior relativização das garantias

\footnotetext{
${ }^{9}$ SILVA FILHO, Edson Vieira da. A relativização das garantias penais ou: quem tem medo do garantismo penal? In: STRECK, Lenio Luiz (Org.). A discricionariedade nos sistemas jurídicos contemporâneos. Bahia: Editora Jus Podivm, 2017.

${ }^{10}$ O Estado Moderno sofreu uma difícil transição. No mundo contemporâneo da pós-modernidade os conceitos do Estado Moderno são esvaziados e dão lugar ao constitucionalismo. Esse constitucionalismo contemporâneo, por sua vez, transforma a ordem estatal e procura aperfeiçoar a democracia, ampliando os valores de liberdade. Aqueles conceitos do Estado Moderno, tais como "soberania, cidadania, contrato social, constituição e legalidade, representação, parlamentarismo e magistraturas etc. - são esvaziados de sua substância". In: GOYARD-FABRE, Simone. Os princípios filosóficos do direito político moderno. São Paulo: Martins Fontes, 2002. P. 435.

${ }^{11}$ SILVA, Marina Helena Vieira da. POSTERARO, Talita Piedade. Tolerância Zero. In: SILVA FILHO, Edson Vieira da (Org.). O Direito Penal e suas faces: Da modernidade ao Neoconstitucionalismo: Volume 2 - O Direito Penal visto de uma perspectiva maximalista. São Paulo: Lexia, 2013.
} 
penais. No entanto, isso é incompatível com o constitucionalismo contemporâneo brasileiro e com a ideia de um direito penal e processual penal garantista e de base humanitária. ${ }^{12}$

No contexto brasileiro, a Constituição Federal, Carta Magna do ordenamento jurídico, traz em seu artigo 1 ${ }^{\text {a }}$, Caput, a definição do Brasil como sendo um Estado Democrático de Direito e, dessa forma, é a partir dele que decorrem todos os princípios fundamentais do Estado. ${ }^{13}$ Ela prevê implicitamente um direito penal mínimo, compreendido como a última ratio do sistema e que deve ser aplicado somente quando os outros meios de garantias e as outras áreas do direito mostrarem-se ineficazes ou insuficientes. Sendo assim, é a partir desse princípio que decorre o caráter fragmentário do direito penal e sua natureza subsidiária ${ }^{14}$.

No entanto, embora o Princípio da Intervenção Mínima seja a base do direito penal Brasileiro, o Estado, na busca para dar uma resposta à sociedade sobre a crescente violência social, mais visível nas grandes cidades mas generalizada por todo o país, nota-se uma forte tendência de uma adoção quase que oficial (estruturada a partir de metadiscursos e metraregras) de um sistema penal cada vez mais rígido, que pode ser incluído entre as vertentes maximalistas penais. Este modelo de direito penal máximo, de maneira geral, é marcado pela rigorosa repressão de pequenos delitos ${ }^{15}$ e está ligado à tese do direito penal do inimigo - que tem como seu principal expoente Günter Jakobs. ${ }^{16}$

Nesse sentido, na busca para encontrar soluções para poder conter os deserdados, aqueles esquecidos pelo modelo neoliberal, e acalmar os anseios sociais, a solução encontrada pelo Estado é o direito penal máximo - política criminal extremamente repressiva -, em

\footnotetext{
${ }^{12}$ SILVA FILHO, Edson Vieira da. A relativização das garantias penais ou: quem tem medo do garantismo penal? In: STRECK, Lenio Luiz (Org.). A discricionariedade nos sistemas jurídicos contemporâneos. Bahia: Editora Jus Podivm, 2017.

${ }^{13}$ ESPÍNDOLA, Ruy Samuel. A constituição de 1988 como garantia da democracia brasileira - O papel dos princípios constitucionais (aportes comemorativos de seus 25 anos). Revista Brasileira de Direito Eleitoral RBDE. Belo Horizonte, ano 5, n. 9, jul./dez. 2013.

${ }^{14}$ LUISI, Luiz Benito Viggiano. Os Princípios Constitucionais Penais. Porto Alegre: Sérgio Antônio Fabris, 2003.

${ }^{15}$ É a ideia da progressão delitiva e da crença generalizada de que a tolerância de pequenos delitos permitirá o cometimento de grandes delitos. A não repressão, além de multiplicar os delitos também gera um aumento da sua gravidade. Dessa forma, somente o controle das pequenas infrações faz com que as grandes infrações não venham a ocorrer. É a própria ideia da Teoria das Janelas Quebradas, que compreende que se os pequenos delitos não forem punidos, isso irá gerar, como consequência, o cometimento de mais crimes e mais severos, ante o descaso do Estado em punir as condutas consideradas menos gravosas.

${ }^{16}$ SILVA, Marina Helena Vieira da. POSTERARO, Talita Piedade. Tolerância Zero. In: SILVA FILHO, Edson Vieira da (Org.). O Direito Penal e suas faces: Da modernidade ao Neoconstitucionalismo: Volume 2 - O Direito Penal visto de uma perspectiva maximalista. São Paulo: Lexia, 2013.
} 
contraposição ao modelo garantista, baseado na intervenção penal mínima e que tem como fundamento a própria Constituição da República Federativa do Brasil de 1988.

Desse modo, para fazer frente à criminalidade violenta, as sociedades modernas, cada vez mais, vem adotando políticas e discursos criminais com o objetivo de manter a ordem e a segurança da sociedade. Diante disso, pode-se destacar que o direito penal contemporâneo vem sofrendo muitas mudanças frente ao choque entre os anseios de ordem e segurança, confrontados com os anseios de igualdade e liberdade de um Estado Democrático. ${ }^{17}$ Nos últimos anos, a sociedade, incentivada pelas mídias, revigorou o seu ânimo de adotar um maior rigor a repressão penal, defendendo uma cultura punitivista que enxerga no direito penal o melhor e mais eficiente instrumento de resposta ao problema da criminalidade. ${ }^{18}$

Sendo assim:

Uma das características da sociedade globalizada é a influência cada vez maior dos meios de comunicação de massa nos processos de formação da opinião sobre os mais diversos assuntos. (...) o medo de tornar-se vítima de um delito, transforma-se em mercadoria da indústria cultural (...). ${ }^{19}$

Nesse sentido, é possível perceber que no Brasil as reformas que estão ocorrendo na esfera do direito penal são, em sua grande maioria, da influência cada vez maior dos meios de comunicação em massa. Eles influenciam na formação da opinião pública acerca do crime e da criminalidade, por meio de discursos repressivos intencionados a atender a nova realidade social $^{20}$. E isso é de se esperar, já que o medo sempre é grande aliado das intâncias de poder e de controle social e a promoção do caos social é e sempre foi um maquiavélico e forte aliado do discurso da força.

Uma sociedade acuada e amedrontada pela criminalidade (que existe e conturba a paz social) e pela violência urbana (também preocupante) pode ser considerado o cenário ideal para o desenvolvimento midiático de um direito penal maximalista (e é aqui que se encontra o cerne da discussão). A sensação de pânico generalizada cria, através de dados estatísticos que além

\footnotetext{
${ }^{17}$ CARNEIRO NETO, Durval. O mal estar do direito penal na pós modernidade. Revista brasileira de direito público- RBDP. Belo Horizonte, ano 14, n. 55, out./dez. 2016.

${ }^{18}$ REALE JÚNIOR, Miguel. Novos rumos do sistema criminal. Rio de Janeiro: Editora Forense, 1983. P. 40.

19 WERMUTH, Maiquel Ângelo Dezordi. Medo e Direito Penal: Reflexos da expansão punitiva na realidade brasileira. Porto Alegre: Livraria do Advogado. 2011. P.44.

${ }^{20}$ CALLEGARI, André Luís; WERMUTH, Maiquel Ângelo Dezordi. Crime organizado: conceito e possibilidade de tipificação diante do contexto de expansão do direito penal. Revista brasileira de Ciências Criminais. São Paulo, 2009, vol. 17, n.79. p.7-40.
} 
de pobres $^{21}$ são sistematicamente mal interpretados e de informações distorcidas divulgadas pela mídia um sentimento global de insegurança ou todos contra o inimigo. ${ }^{22} \mathrm{Na}$ verdade, essa discussão parte do mito da eficiência associada ao punitivismo, enquanto ao minimalismo é associado um modelo penal fraco e tolerante. ${ }^{23}$

Sendo assim, estaria de um lado um direito penal eficiente, que se anuncia como apto a atender os anseios sociais e controlar a criminalidade. Já do outro lado, um direito pautado na mínima intervenção penal e portanto ineficaz no controle criminal. Dessa forma, o direito penal máximo corresponderia melhor a sociedade que clama por mais punição. A perspectiva minimalista - que tem como seu principal expoente Luigi Ferrajoli e que idealiza um sistema penal garantista - é fundamentada nos discursos da mínima intervenção penal e defende que ele deve ser aplicado somente como ultima ratio, pois deveria haver uma limitação ao poder incriminador do Estado e, diante disso, é geralmente considerada como uma vertente fraca do direito penal. ${ }^{24}$

Assim, há um contexto emergencial do direito penal, que surge no âmbito da globalização, e que faz com que o Estado vise controlar os seus "deserdados". Ele se utiliza de modelos penais maximalistas para conter o clima de insegurança gerado por essa parcela da sociedade e deixa de observar a aplicação do direito penal mínimo. ${ }^{25}$ No entanto, essas medidas de emergência se configuram em um fenômeno que demonstra a incapacidade do Estado de lidar com o problema da criminalidade e, assim, ele se utiliza de medidas excepcionais que com o tempo acabam definitivamente se incorporando ao ordenamento jurídico. ${ }^{26}$

\footnotetext{
${ }^{21} \mathrm{Na}$ criminoligia existe a denominação "cifra negra", para representar os casos que não chegam ao conhecimento público. Isso demonstra que os níveis de criminalidade não são aqueles que são oficialmente registrados e que há uma falha nas estatísticas oficiais.

${ }^{22}$ SICA, Leonardo. Direito penal de emergência e alternativas a prisão. São Paulo: Editora Revista dos Tribunais, 2002. P. 77-80.

${ }^{23}$ SILVA, Marina Helena Vieira da. POSTERARO, Talita Piedade. Tolerância Zero. In: SILVA FILHO, Edson Vieira da (Org.). O Direito Penal e suas faces: Da modernidade ao Neoconstitucionalismo: Volume 2 - O Direito Penal visto de uma perspectiva maximalista. São Paulo: Lexia, 2013.

${ }^{24}$ SILVA FILHO, Edson Vieira da. Minimalismo penal: uma reflexão crítica a partir de Eugenio Raúl Zaffaroni "Em busca das penas perdidas". In: SILVA FILHO, Edson Vieira da (Org.). O Direito Penal e suas faces: Da Modernidade ao Neoconstitucionalismo - Volume 1: O Direito Penal visto em uma perspectiva minimalista. Curitiba: Editora CRV, 2012.

${ }^{25}$ FERNANDES, Luciana de Medeiros. Direito penal máximo ou intervenção mínima do direito penal? Breves lineamentos sobre a função do direito penal. São Paulo: Editora Revista dos Tribunais, 2007.

${ }^{26}$ SICA, Leonardo. Direito penal de emergência e alternativas a prisão. São Paulo: Editora Revista dos Tribunais, 2002.
} 
Desse modo, pode-se compreender que o direito penal mínimo, nos moldes propostos por Zaffaroni, e como Streck também busca desenhar como constitucionalmente adequado no Brasil, protege o cidadão ${ }^{27}$ contra o ius puniendi estatal, não se encaixa no tipo de controle social reivindicado pelas sociedades modernas por terem um alto grau de fetiche pelo controle como meio de construir respostas ideais para problemas concretos. Em contrapartida ao permitido pelo direito penal máximo, em que há (pelo menos uma expectatativa) da violação dos direitos e das garantias fundamentais do indivíduo que seja considerado inimigo do Estado. ${ }^{28}$ De acordo com Ferrajoli, pode-se compreender que o direito penal máximo é aquele caracterizado como um modelo incondicionado, ilimitado e extremamente severo. Diante da incerteza e da imprevisibilidade das condenações ele se configura como um sistema incontrolável e não respeita nem mesmo as garantias e os direitos fundamentais. ${ }^{29}$

A ideia de um direito penal mais eficiente, baseada no atual momento de aumento da criminalidade nas sociedades, enseja intolerância às práticas delituosas e corrobora a perspectiva de um sistema penal mais intervencionista e controlador. No entanto, esse direito penal máximo vai de encontro ao pensamento de outras correntes do direito, como a abolicionista e a minimalista. Enquanto essas duas correntes são favoráveis à diminuição da interferência penal, os maximalistas procuram aumentar a tutela dos bens jurídicos protegidos pelo direito penal. ${ }^{30}$

A grande questão esquecida está delineada desde a superfície do sistema brasileiro, sem que sequer seja necessário ir a fundo para ver outras (e mais sérias) incongruências: Em um modelo social baseado na tolerância (isso é constitucional) não se pode fundar um direito penal a partir da tolerância zero. Como consequência do maximalismo penal, surge naturalmente o fenômeno denominado de "expansionismo penal". Uma vez que o Estado e as sociedades

\footnotetext{
${ }^{27}$ No sentido mais amplo que se pode dar à expressão "cidadão", talvez até chegando ao que pretende Muller em "Quem é o povo?".

${ }^{28}$ FERNANDES, Luciana de Medeiros. Direito penal máximo ou intervenção mínima do direito penal? Breves lineamentos sobre a função do direito penal. São Paulo: Editora Revista dos Tribunais, 2007.

${ }^{29}$ FERRAJOLI, Luigi. Direito e Razão: Teoria do garantismo penal. $4^{a}$ Ed. São Paulo: Revista dos Tribunais, 2014.

${ }^{30}$ SILVA FILHO, Edson Vieira da. Minimalismo penal: uma reflexão crítica a partir de Eugenio Raúl Zaffaroni "Em busca das penas perdidas". In: SILVA FILHO, Edson Vieira da (Org.). O Direito Penal e suas faces: Da Modernidade ao Neoconstitucionalismo - Volume 1: O Direito Penal visto em uma perspectiva minimalista. Curitiba: Editora CRV, 2012.
} 
modernas enxergam o direito penal como o único/primeiro/mais eficiente instrumento para conter violações sociais.

\section{REFLEXOS DO DIREITO PENAL CONTEMPORÂNEO: O FENÔMENO DO EXPANSIONISMO PENAL}

Bauman, ao descrever as sociedades pós-modernas, aborda a ilusão das pessoas com a promessa de que os terrores que atormentavam a vida social no passado seriam superados e que todos poderiam controlar suas próprias vidas. No entanto, ao contrário disso, no século XXI voltou-se a viver uma "época do medo". Medo dos atentados terroristas, da violência urbana, dos desastres ambientas, entre outros. Esses acabaram por induzir na sociedade um sentimento constante de que a qualquer momento eles podem ser atingidos por algum perigo. ${ }^{31}$ Silva Sánchez caracteriza a sociedade atual como uma sociedade da "insegurança sentida" ou "sociedade do medo", vez que, segundo ele, a sensação de insegurança permeia entre os cidadãos. $^{32}$

Na seara penal, o medo acaba culminando por reproduzir o aumento do temor e do estímulo das taxas de criminalidade. Impulsionado pela mídia, ele dispensa maiores elaborações e aceita políticas criminais que, na grande maioria das vezes, são transigentes com as garantias penais e processuais penais daquele que viola as normas. ${ }^{33}$ A partir disso, a sociedade moderna produziu os seus estranhos, indivíduos que se tornaram o alvo da ânsia criminalizadora do Estado. A decorrência disso foi um fenômeno que acabou por provocar um expansionismo penal, uma vez que o Estado enxerga o direito penal como única forma de combater esse avanço da criminalidade. ${ }^{34}$

\footnotetext{
${ }^{31}$ BAUMAN, Zygmunt. Medo liquido. Trad. Carlos Alberto Medeiros. Rio de Janeiro: Zahar, 2008.

${ }^{32}$ SILVA SÁNCHEZ, Jesús-María. A expansão do direito penal: aspectos da política criminal nas sociedades pósindustriais. Trad. Luiz Otávio de Oliveira Rocha. São Paulo: Revista dos Tribunais, 2013. P. 40.

${ }^{33}$ CORNELLI, Roberto. Miedo, criminalidad y orden. Buenos Aires: IBdeF, 2012.

${ }^{34}$ SILVA SÁNCHEZ, Jesús-María. A expansão do direito penal: aspectos da política criminal nas sociedades pósindustriais. Trad. Luiz Otávio de Oliveira Rocha. São Paulo: Revista dos Tribunais, 2013.
} 
Nesse sentido, as sociedades contemporâneas, sentindo-se ameaçadas pelo aumento dos índices de criminalidade, passam a vivenciar um momento de (hiper)inflação legislativa na esfera penal. Esse fato decorre de várias causas, mas especialmente pelas novas condutas ilícitas que surgiram junto com a ascensão do fenômeno da globalização. Essa ensejou a criação de novos tipos penais, bem como promoveu o recrudescimento dos que já existiam e, disso, promoveu o expansionismo penal. ${ }^{35}$ Se é fato que novas condutas que merecem contenção penal surgem, também deve-se deixar claro que nem tudo que é novo deve ser contido e muito menos receber uma resposta penal.

O Professor Catedrático de direito penal da Universidade de Pompeu Fabra, na Espanha, Jesús-Maria Silva Sanchez, expõe em sua obra "A expansão do direito penal" acerca desse fenômeno que surge em decorrência do expansionismo penal. Ele apresenta quais seriam as possíveis causas do avanço desse ramo do direito nas sociedades modernas. Além disso, aborda acerca daquilo que denomina de "velocidades do direito". 36

Silva Sánchez ressalta o papel incisivo do Estado no desenvolvimento do fenômeno de expansão do direito penal. Esse autor afirma que essa referida expansão se revela como fruto de uma perversidade estatal que busca no permanente recurso à legislação penal uma aparente solução fácil aos problemas sociais. ${ }^{37}$

\begin{abstract}
Ali onde chovem leis penais continuadamente, onde por qualquer motivo surge entre o público um clamor geral de que as coisas se resolvam com novas leis penais ou agravando as existentes, aí não se vivem os melhores tempos para a liberdade - pois toda lei penal é uma sensível intromissão na liberdade, cujas consequências serão perceptíveis também para os que a exigiram da forma mais ruidosa -, ali se pode pensar na frase de Tácito: péssima respublica, plurimae leges. ${ }^{38}$
\end{abstract}

A partir das palavras do autor pode-se compreender melhor acerca do papel incisivo que pode ser desempenhado pela legislação penal. Ao chamar a atenção para as possíveis causas do expansionismo penal, Silva Sánchez afirma que o surgimento de novos bens jurídicos e até novas formas de violar bens jurídicos clássicos necessitariam de novas formas de proteção

\footnotetext{
${ }^{35}$ BONACCORSI, Daniela Villani. Constitucionalismo e emergencialismo penal: progresso global e retrocesso democrático. Revista do instituto de hermenêutica jurídica - RIHJ, v. 11, n.13, p. 165-186, jan./jun. 2013.

${ }^{36}$ SILVA SÁNCHEZ, Jesús-María. A expansão do direito penal: aspectos da política criminal nas sociedades pósindustriais. Trad. Luiz Otávio de Oliveira Rocha. São Paulo: Revista dos Tribunais, 2013.

${ }^{37}$ SILVA SÁNCHEZ, Jesús-María. A expansão do direito penal: aspectos da política criminal nas sociedades pósindustriais. Trad. Luiz Otávio de Oliveira Rocha. São Paulo: Revista dos Tribunais, 2013.

${ }^{38}$ SILVA SÁNCHEZ, Jesús-María. A expansão do direito penal: aspectos da política criminal nas sociedades pósindustriais. Trad. Luiz Otávio de Oliveira Rocha. São Paulo: Revista dos Tribunais, 2013. P. 25.
} 
penal. Ademais, o autor ainda atribui a culpa da insegurança social aos meios de comunicação, pois em seu entender existe aí uma correlação, pois a mídia ocupa uma posição de privilegio na sociedade da informação. ${ }^{39}$

Além disso, o descrédito das demais instâncias de proteção é outro fato que para Silva Sánchez pode ser somado às causas da expansão penal. Nesse sentido, são vários os fatores que indicam que somente o direito penal seria capaz de resolver os "problemas" sociais. Essa situação gera um resultado que, no entender do autor, é desalentador, que é o abandono da ideia do direito penal como ultima ratio. E, não apenas por isso, mas também porque essa expansão é em boa parte inútil, à medida que transfere ao direito penal um fardo que ele não pode carregar. $^{40}$

É sombria a constatação de que o sistema penal acaba por desempenhar a função de ter que controlar as "populações incômodas" - os desviantes e criminosos - e de que para essa tentativa ele se alia à mídia para alimentar, no entender de Wacquant, uma próspera indústria cultural do medo dos pobres. Através do intermédio das mídias de massa o crime passa a ser percebido como um fenômeno muito mais presente no âmbito social do que ele realmente é na vida de grande parte das pessoas. A partir disso, ele passa a produzir, na opinião pública, uma supervaloração dos riscos. ${ }^{41}$

No entanto, é preciso destacar que a busca pelo ideal da segurança não pode ser motivo ensejador de mudanças no paradigma constitucional de liberdade e dos fundamentos de legitimidade do Estado Democrático de Direito, pois isso não justifica o aumento ilimitado dos poderes estatais e a redução de direitos e garantias. ${ }^{42}$

No plano político, o endurecimento e o expansionismo das políticas criminais por meio do direito penal se dá também através das propostas de criação de um direito penal de segunda

\footnotetext{
${ }^{39}$ SILVA SÁNCHEZ, Jesús-María. A expansão do direito penal: aspectos da política criminal nas sociedades pós- industriais. Trad. Luiz Otávio de Oliveira Rocha. São Paulo: Revista dos Tribunais, 2013.

${ }^{40}$ SILVA SÁNCHEZ, Jesús-María. A expansão do direito penal: aspectos da política criminal nas sociedades pós- industriais. Trad. Luiz Otávio de Oliveira Rocha. São Paulo: Revista dos Tribunais, 2013.

${ }^{41}$ WACQUANT, Loïc. Os excluídos da sociedade de consumo: toxicodependentes, psicopatas e sem-abrigo nas prisões americanas. Anál. Social, Lisboa, n. 185, P. 987-1003, 2007. Disponível em: http://www.scielo.mec.pt/scielo.php?script=sci_arttext\&pid=S0003-25732007000400002\&lng=en\&nrm=iso. Acesso em 19 abr. 2020.

${ }^{42}$ VAZ, Paulo Afonso Brum. O sistema penal e o medo do crime: influência midiática, retirada do Estado Social, políticas criminais e expansionismo. Revista de Doutrina da $4^{a}$ Região, Porto Alegre, n.70, fev. 2016. Disponível em: https://revistadoutrina.trf4.jus.br/artigos/edicao070/PauloAfonso_Vaz.html. Acesso em: 19 abr. 2020.
} 
e até de terceira velocidade e com o direito penal do inimigo. Esses se constituem em artifícios que, sem sucesso, procuram recuperar o consenso cidadão e apresentam estratégias que apelam para a relação segurança/liberdade, que exerce uma função importante no convencimento da sociedade pelo discurso do medo. A ideia é a de que a segurança se obtém a partir da restrição da liberdade. ${ }^{43}$

É de Jesús-Maria Silva Sanchez a ideia das "velocidades do direito penal". Conforme esse autor o direito penal moderno teria três velocidades. A primeira estaria caracterizada pela pena de prisão, seguindo o modelo de direito penal liberal clássico, que se utiliza preferencialmente da pena privativa de liberdade, mas que se funda em garantias individuais. E, como Sánchez ainda afirma, são mantidos rigidamente os princípios político-criminais clássicos, as regras de imputação e os princípios processuais. ${ }^{44}$

Já quanto a segunda velocidade do direito penal, essa considera que aos delitos socioeconômicos são imputadas as penas privativas de liberdade e devem ser respeitados todos os direitos, garantias e princípios processuais. Essa velocidade do direito penal abarca o modelo que incorpora duas tendências: a flexibilização proporcional de determinadas garantias penais e processuais aliadas à adoção de medidas alternativas à prisão - ou seja, para os casos em que, por não se tratar de prisão, senão de penas de privação de direitos ou pecuniárias, os princípios e regras podem experimentar uma flexibilização proporcional à menor intensidade da sanção. ${ }^{45}$

Por fim, tem então a terceira velocidade do direito penal. Essa possui uma estreita relação com a Teoria idealizada por Günther Jakobs, do direito penal do inimigo. Essa velocidade refere-se a uma combinação entre as características da primeira e segunda velocidades. Isso porque ela considera a pena privativa de liberdade (como faz o direito penal de primeira velocidade), mas ao mesmo tempo também permite a flexibilização de garantias materiais e processuais (o que ocorre no âmbito do direito penal de segunda velocidade). ${ }^{46}$

\footnotetext{
${ }^{43}$ HASSEMER, Winfried. Por qué no debe suprimirse el Derecho Penal. México: Instituto Nacional de Ciencias Penales, 2003.

${ }^{44}$ SILVA SÁNCHEZ, Jesús-María. A expansão do direito penal: aspectos da política criminal nas sociedades pósindustriais. Trad. Luiz Otávio de Oliveira Rocha. São Paulo: Revista dos Tribunais, 2013.

${ }^{45}$ SILVA SÁNCHEZ, Jesús-María. A expansão do direito penal: aspectos da política criminal nas sociedades pósindustriais. Trad. Luiz Otávio de Oliveira Rocha. São Paulo: Revista dos Tribunais, 2013.

${ }^{46}$ SILVA SÁNCHEZ, Jesús-María. A expansão do direito penal: aspectos da política criminal nas sociedades pósindustriais. Trad. Luiz Otávio de Oliveira Rocha. São Paulo: Revista dos Tribunais, 2013.
} 
Nesse sentido, pode-se compreender que uma consequência direta desse fenômeno do expansionismo penal é a proliferação desenfreada de leis penais:

\begin{abstract}
As características principais da política criminal praticada nos últimos anos podem resumir-se no conceito da "expansão" do direito penal. Efetivamente, no momento atual pode ser adequado que o fenômeno mais destacado na evolução atual das legislações penais do "mundo ocidental" está no surgimento de setores inteiros de regulação, acompanhada de uma atividade de reforma de tipos penais já existentes, realizada a um ritmo muito superior ao de épocas anteriores. ${ }^{47}$
\end{abstract}

E foi nesse cenário que surgiu a teoria do direito penal do inimigo, que tem como seu principal expoente Günter Jakobs. Muito provavelmente, nas últimas décadas, essa foi a teoria que mais causou polêmica no seio da comunidade jurídica e despertou, em sua grande maioria, reações críticas baseadas, principalmente, no fundamento de que ela seria ela incompatível com um Estado de Direito e que também seria uma prática de disseminação do medo.

\title{
3. UMA AMEAÇA AO ESTADO DEMOCRÁTICO: O DIREITO PENAL DO INIMIGO
}

Como consequência do maximalismo e do expansionismo penal, tem-se o chamado direito penal do inimigo. Essa teoria, idealizada por Günter Jakobs, determina alguns cidadãos como "inimigos da sociedade", ou seja, aqueles que romperam com o pacto social, os quais demandam um tratamento repressivo maior, que lhes nega garantias penais e processuais penais. Para esse autor, o direito penal do inimigo indica o inimigo como uma não pessoa, como alguém que não pode receber o mesmo tratamento destinado aos cidadãos, ele não pode beneficiar-se das garantias. ${ }^{48}$

A expressão "direito penal do inimigo" passou a ser utilizada inicialmente por volta da década de 1980, mas o seu desenvolvimento teórico e filosófico somente ganhou corpo a partir da década de 1990. A sua teoria ganhou maior destaque depois de $2001 \mathrm{com}$ a onda de ataques terroristas ao redor do mundo, mais precisamente após o 11 de setembro, com o atentando às

\footnotetext{
${ }^{47}$ JAKOBS, Günther; MELIÁ, Manuel Cancio. Direito penal do inimigo, noções e críticas. Tradução de André Luis Callegari e Nobreu José Giancomolli. 2 ed. Cidade: Editora Livraria do Advogado. 2007. P. 55-56.

${ }^{48}$ JAKOBS, Günther; MELIÁ, Manuel Cancio. Direito penal do inimigo, noções e críticas. Tradução de André Luis Callegari e Nobreu José Giancomolli. 2 ed. Cidade: Editora Livraria do Advogado. 2007.
} 
torres gêmeas. É nesse período que Gunther Jakobs faz com que o direito penal do inimigo ganhe mais espaço. ${ }^{49}$

Sendo assim, o direito penal do inimigo é uma teoria defendida por alguns estudiosos que tem na pessoa de Günther Jakobs, penalista e filósofo alemão, o seu principal defensor. Essa teoria, construída a partir de uma base contratualista, parte do pressuposto de se dividir o direito penal em dois polos: de um lado um direito penal direcionado ao cidadão criminoso comum (que tem todos os seus direitos e garantias resguardados) e do outro lado um direito para o inimigo (que seria o infrator reiterado e perigoso).$^{50}$ Nesse sentido:

\begin{abstract}
Parte da ideia de que há dois tipos de criminosos: o cidadão criminoso comum, que cometeu um crime e que será punido para que a norma criminal seja reafirmada; e o inimigo, um ser que, deliberadamente, renega o Estado e a sociedade - que continuará atentando contra eles e, nesse caso, aplicam-se medidas de contenção com o fim de segregá-lo do convívio social, haja vista sua periculosidade - o risco de sua liberdade. Haveria, portanto, um direito penal do cidadão e um direito penal do inimigo, entendendo-se essa distinção mais como modos de compreender o mundo e o direito do que uma separação legislativa clara. ${ }^{51}$
\end{abstract}

Desse modo, essa teoria compreende que aquele que viola as leis deve ser visto como um inimigo do Estado. Ele não pode gozar dos mesmos direitos e garantias daqueles que "cumprem seus deveres". Sendo assim, defende que deve ser dado a esses um tratamento diferenciado entre as pessoas e os considerados inimigos. ${ }^{52}$ Essa ideia do direito penal do inimigo, da teoria de Jakobs, já poderia ser vislubrada a partir Rosseau, Kant e Hobbes, que influenciaram na construção dessa ideia de inimigo do Estado e da segregação dos indivíduos em bons e maus.

Em diversas passagens de sua obra, "direito penal do inimigo" Jakobs deixa clara a influência dos filósofos contratualistas:

São especialmente aqueles autores que fundamentam o Estado de modo estrito, mediante um contrato, entendem o delito no sentido de que o delinquente infringe $o$

\footnotetext{
49 ALVES, Daniel Limongi Alvarenga. CARVALHO JÚNIOR, Rovilson Marques de. Direito penal do inimigo. In: SILVA FILHO, Edson Vieira da (Org.). O Direito Penal e suas faces: Da modernidade ao Neoconstitucionalismo: Volume 2 - O Direito Penal visto de uma perspectiva maximalista. São Paulo: Lexia, 2013.

${ }^{50}$ ZAFFARONI, Eugenio Raúl. O inimigo no direito penal. Trad. Sérgio Lamarão. Rio de Janeiro: Revan. 2007.

${ }^{51}$ STRECK, Lenio Luiz. SANTOS JÚNIOR, Rosivaldo Toscano dos. Do Direito Penal do Inimigo ao Direito Penal do Amigo do Poder. Revista de Estudos Criminais 51, Doutrina Nacional. Out./Dez. 2013. Acesso em http://www.bdr.sintese.com/AnexosPDF/REC\%2051\%20-\%20doutrina\%20nacional.pdf Acessado em 01 mai. 2020.

${ }^{52}$ ZAFFARONI, Eugenio Raúl. O inimigo no direito penal. Trad. Sérgio Lamarão. Rio de Janeiro: Revan, 2007.
} 
contrato, de maneira que já não participa dos benefícios deste: a partir desse momento, já não vive com os demais dentro de uma relação jurídica. ${ }^{53}$

A partir do contexto de altos índices de criminalidade (especialmente após os anos 2000) surge a ideia de que certas pessoas, por seus atos de reiterada negação da norma e pelo perigo que representam à sociedade, deveriam ser vistas pelo Estado como inimigos. Esses indivíduos perderiam a sua personalidade, deixando de ser pessoas e passariam a ser tratadas como inimigos, sem direitos e alçados à condição de mero objeto de punição. ${ }^{54}$

Pode-se compreender então que o papel do direito penal do inimigo é o de eliminar o perigo que estes (inimigos, não cidadãos) representam a sociedade. Neste contexto do Estado Moderno, o inimigo é considerado como não pessoa, ele faz parte de grupos que são indesejados pela sociedade, que devem ser excluídos do contexto social, pois perdem o seu status de pessoa em nome da proteção da maioria, dos "homens de bem".

Além disso, pode-se compreender a teoria do direito penal do inimigo é fundamentada sobre três pilares: a antecipação da punição do inimigo; a desproporcionalidade das penas e a relativização ou supressão de garantias penais e processuais penais; e, por fim, a criação de leis mais severas destinadas à clientela penal (terroristas, delinquentes, traficantes, dentre outros) específica do controle social. ${ }^{55}$

Diante disso, podem ser compreendidas como características do direito penal do inimigo, entre outras: a antecipação da punibilidade com a tipificação de atos preparatórios; a criação de novos tipos penais; a criação de tipos de mera conduta e de perigo abstrato; a desproporcionalidade das penas; a restrição de garantias penais e processuais penais. ${ }^{56}$

Além disso, essa teoria também tem como ideal que o inimigo é punido não apenas por aquilo que ele fez ou necessariamente deixou de fazer, mas, ele é punido por aquilo que ele

\footnotetext{
${ }^{53}$ JAKOBS, Günther; MELIÁ, Manuel Cancio. Direito penal do inimigo, noções e críticas. Tradução de André Luis Callegari e Nobreu José Giancomolli. 2 ed. Cidade: Editora Livraria do Advogado. 2007. P. 25.

${ }^{54}$ ZAFFARONI, Eugenio Raúl. O inimigo no direito penal. Trad. Sérgio Lamarão. Rio de Janeiro: Revan, 2007.

${ }^{55}$ ALVES, Daniel Limongi Alvarenga. CARVALHO JÚNIOR, Rovilson Marques de. Direito penal do inimigo. In: SILVA FILHO, Edson Vieira da (Org.). O Direito Penal e suas faces: Da modernidade ao Neoconstitucionalismo: Volume 2 - O Direito Penal visto de uma perspectiva maximalista. São Paulo: Lexia, 2013.

${ }^{56}$ ALVES, Daniel Limongi Alvarenga. CARVALHO JÚNIOR, Rovilson Marques de. Direito penal do inimigo. In: SILVA FILHO, Edson Vieira da (Org.). O Direito Penal e suas faces: Da modernidade ao Neoconstitucionalismo: Volume 2 - O Direito Penal visto de uma perspectiva maximalista. São Paulo: Lexia, 2013.
} 
pode vir a praticar e que cause temor à sociedade. O inimigo é considerado aquele que constantemente afronta o Estado, com o intuito de desestabilizar a sua ordem. ${ }^{57}$ Silva Sánchez esclarece como se dá a transição do cidadão ao inimigo e, para ele, esta seria produzia mediante a reincidência, a habitualidade, a delinquência profissional e, finalmente, a integração em organizações delitivas estruturadas. ${ }^{58}$

Para o considerado inimigo da sociedade ficam suprimidas as garantias penais e processuais penais e também os seus direitos constitucionais, como o contraditório, a ampla defesa, a constituição de defensor, entre outros. Isso tendo-se em vista que ele representa uma ameaça para os demais e para a segurança e ordem pública. No entanto, essas práticas são incompatíveis com um Estado Democrático de Direito e com o Brasil contemporâneo.

No entanto, embora a base do direito penal brasileiro seja a intervenção penal mínima, pode-se verificar um enrijecimento do sistema penal e a supressão de direitos e garantias fundamentais do cidadão considerado como inimigo do Estado. É importante ressaltar que, para Zaffaroni, o conceito de inimigo nunca é compatível com um Estado Democrático de Direito e nem com os princípios do liberalismo político. ${ }^{59}$

Ainda, de acordo com Zaffaroni, a essência do tratamento diferenciado que se atribui ao inimigo consiste em que o direito lhe nega sua condição de pessoa, sendo considerado sob o aspecto de ente perigoso. Essa ideia propõe estabelecer uma distinção entre cidadãos (pessoas) e inimigos (não-pessoas). No caso, o inimigo é privado de certos direitos individuais, motivo pelo qual ele deixa de ser considerado pessoa e é por isso que a ideia de direito penal do inimigo é incompatível com um Estado de Direito. ${ }^{60}$

A essência do tratamento diferenciado que se atribui ao inimigo consiste em que o direito lhe nega sua condição de pessoa. Ele só é considerado sob o aspecto de ente perigoso ou daninho. Por mais que a ideia seja matizada, quando se propõe estabelecer a distinção entre cidadãos (pessoas) e inimigos (não pessoas), faz-se referência a seres humanos que são privados de certos direitos individuais, motivo pelo qual deixaram

\footnotetext{
${ }^{57}$ SILVA FILHO, Edson Vieira da. A relativização das garantias penais ou: quem tem medo do garantismo penal? In: STRECK, Lenio Luiz (Org.). A discricionariedade nos sistemas jurídicos contemporâneos. Bahia: Editora Jus Podivm, 2017.

${ }^{58}$ SILVA SÁNCHEZ, Jesús-María. A expansão do direito penal: aspectos da política criminal nas sociedades pós-industriais. Trad. Luiz Otávio de Oliveira Rocha. 2. ed. São Paulo: Revista dos Tribunais, 2011.

${ }^{59}$ ZAFFARONI, Eugenio Raúl. O inimigo no direito penal. Trad. Sérgio Lamarão. Rio de Janeiro: Revan, 2007.

${ }^{60}$ ZAFFARONI, Eugenio Raúl. O inimigo no direito penal. Trad. Sérgio Lamarão. Rio de Janeiro: Revan, 2007.
} 
de ser considerados pessoas, e esta é a primeira incompatibilidade que a aceitação do hostis, no direito, apresenta com relação ao princípio do Estado de Direito.61

Apesar disso, esses discursos, cada vez mais, encontram receptividade na sociedade brasileira. Os meios de comunicação são utilizados como mecanismos de promoção de medidas emergenciais para elevar a função simbólica de um sistema penal eminentemente repressivo ${ }^{62}$. Alessandro Baratta é um dos autores que questiona essa função simbólica do direito penal, ele aborda que ela tende a prevalecer sobre a função precípua do direito penal e não realiza efetiva proteção de bens jurídicos. Para ele isso se dá pela criação de uma ilusão de segurança e de um sentimento de confiança no ordenamento e nas instituições que possuem uma base real cada vez mais escassa. ${ }^{63}$

Sendo assim, a construção do outro como ameaça, como o inimigo, se faz presente para que se possa negociar rigores e garantias, rompendo com garantias e distribuindo rigores e benesses de maneiras desiguais. Com as premissas maximalistas que são fixadas por uma proposta intolerante e com baixos graus de direitos e garantias, é necessário justificar a ameaça criada por alguns, os malfeitores, os inimigos contra homens de bem(ns). ${ }^{64}$

\section{CONSIDERAÇÕES FINAIS}

O direito penal está vivenciando um claro fenômeno de expansão. Cada vez mais ele considera novas condutas como criminosas e torna mais severas as que já são puníveis. Isso decorre de diversos fatores, sendo que um deles é que, na realidade, o direito penal tem sido cada vez mais pressionado a se expandir. Conforme foi abordado, vivemos em uma sociedade

\footnotetext{
${ }^{61}$ ZAFFARONI, Eugenio Raúl. O inimigo no direito penal. Trad. Sérgio Lamarão. Rio de Janeiro: Revan. 2007. P.18

${ }^{62}$ CALLEGARI, André Luís; WERMUTH, Maiquel Ângelo Dezordi. Crime organizado: conceito e possibilidade de tipificação diante do contexto de expansão do direito penal. Revista brasileira de Ciências Criminais. São Paulo, 2009, vol. 17, n.79.

${ }^{63}$ BARATTA, Alessandro. Criminologia Crítica e Crítica do Direito Penal: introdução à sociologia do direito penal. Trad. Juarez Cirino dos Santos. $3^{\text {a }}$ Ed. Rio de Janeiro: Editora Revan: Instituto Carioca de Criminologia, 2002.

${ }^{64}$ SILVA FILHO, Edson Vieira da. A relativização das garantias penais ou: quem tem medo do garantismo penal? In: STRECK, Lenio Luiz (Org.). A discricionariedade nos sistemas jurídicos contemporâneos. Bahia: Editora Jus Podivm, 2017.
} 
de risco. Se a globalização, a mídia e os avanços tecnológicos provocaram um maior conforto à vida humana, por outro lado trouxeram uma grande sensação de insegurança.

Nesse sentido, o direito penal, como instrumento de controle social, através do controle do indivíduo transgressor e da tipificação das figuras delituosas, consideradas mais nocivas na proteção dos bens jurídicos, separa os indivíduos entre criminosos e sujeitos de bem. Um dos maiores equívocos de tal vertente penal está justamente na ideia da construção do tipo penal a partir do bem e do mal, como se fosse possível dividir a sociedade em homens de bem e homens maus, esquecendo a ordem deontológica de todo o regramento, inclusive o penal de que se trata esse artigo. Cada vez mais se torna perceptível o surgimento de discursos que favorecem um viés maximalista do direito penal, na tentativa de oferecerem uma resposta punitiva eficiente e capaz de gerar acautelamento social.

Essa situação pode levar a conclusão de que a ideia do direito penal como ultima ratio foi senão abandonada, pelo menos relegada a terceiro plano em nome da eficiência de suas respostas. No entanto, na perspectiva do constitucionalismo contemporâneo, esses novos objetivos e concepções do direito penal não podem ser aceitos. Apesar disso, o constitucionalismo contemporâneo brasileiro demonstra dificuldades em gerar um sistema penal que seja adequado a ele e que esteja em consonância com um modelo de Estado Democrático.

Na modernidade, nos encontramos em um cenário que os meios de comunicação estão voltados à ideia de "mais direito penal". Diante disso, embora a Constituição Federal do Brasil preveja um direito penal mínimo, garantista e de base humanitária, o que está na verdade acontecendo é um avanço do maximalismo e da expansão penal. A demanda pelo fortalecimento de práticas repressivas e por uma maior intervenção criminal ganham cada vez mais espaço nos chamados Estado de Direito.

A ideia de um Estado com poder para eleger, ao seu bel-prazer, quem serão os considerados inimigos, apresenta-se como um perigo sem precedentes para um Estado que é considerado Democrático de Direito, como o Brasil. Surge a partir dessa situação perguntas que permanecem sem respostas, quais sejam: como serão determinados os critérios para caracterizar o inimigo? Esses critérios serão modificados com a mudança daqueles que ocupam o poder? O cidadão de hoje poderá ser considerado o inimigo de amanhã? 
Assim, a partir destas questões, é necessário buscar-se referências que efetivamente determinam os desígnios democraticamente escolhidos para servirem como norte de um modelo civilizatório concreto. Os princípios constitucionais acabam por ser determinantes na escolha de um modelo penal e consequentemente no ordenamento positivado que dele decorre. Se o Estado brasileiro, plural, tolerante, includente e estruturado a partir de um núcleo duro de direitos fundamentais, inegociáveis e irredutíveis, é a partir deles que se deve buscar a forma do sistema penal, desde os processos legislativos responsáveis pela produção normativa, pelos processos de criminalização e de descriminalização, até as dinâmicas preventivas, persecutórias processuais e penitenciárias. Esperar novas respostas cometendo os mesmos erros é o retrato da esperança triunfando sobre a experiência. A revisão da estrutura do sistema penal já tarda e não pode ser protelada, sob pena dos altos custos sociais que já se acumulam há muito.

\section{REFERÊNCIAS BIBLIOGRÁFICAS}

ALVES, Daniel Limongi Alvarenga. CARVALHO JÚNIOR, Rovilson Marques de. Direito penal do inimigo. In: SILVA FILHO, Edson Vieira da (Org.). O Direito Penal e suas faces: Da modernidade ao Neoconstitucionalismo: Volume 2 - O Direito Penal visto de uma perspectiva maximalista. São Paulo: Lexia, 2013.

BARATTA, Alessandro. Criminologia Crítica e Crítica do Direito Penal: introdução à sociologia do direito penal. Trad. Juarez Cirino dos Santos. $3^{\mathrm{a}}$ Ed. Rio de Janeiro: Editora Revan: Instituto Carioca de Criminologia, 2002.

BAUMAN, Zygmunt. Medo liquido. Trad. Carlos Alberto Medeiros. Rio de Janeiro: Zahar, 2008.

BECK, Ulrich. Sociedade de Risco: rumo a uma outra modernidade. Trad. Sebastião Nascimento. $2^{\text {a }}$ Ed. São Paulo: 34, 2011.

BONACCORSI, Daniela Villani. Constitucionalismo e emergencialismo penal: progresso global e retrocesso democrático. Revista do instituto de hermenêutica jurídica - RIHJ, v. 11, n.13, p. 165-186, jan./jun. 2013.

CALLEGARI, André Luís; WERMUTH, Maiquel Ângelo Dezordi. Crime organizado: conceito e possibilidade de tipificação diante do contexto de expansão do direito penal. Revista brasileira de Ciências Criminais. São Paulo, 2009, vol. 17, n.79. 
CARNEIRO NETO, Durval. O mal estar do direito penal na pós modernidade. Revista brasileira de direito público- RBDP. Belo Horizonte, ano 14, n. 55, out./dez. 2016.

CORNELLI, Roberto. Miedo, criminalidad y orden. Buenos Aires: IBdeF, 2012.

ESPÍNDOLA, Ruy Samuel. A constituição de 1988 como garantia da democracia brasileira O papel dos princípios constitucionais (aportes comemorativos de seus 25 anos). Revista Brasileira de Direito Eleitoral - RBDE. Belo Horizonte, ano 5, n. 9, jul./dez. 2013.

FERNANDES, Luciana de Medeiros. Direito penal máximo ou intervenção mínima do direito penal? Breves lineamentos sobre a função do direito penal. São Paulo: Editora Revista dos Tribunais, 2007.

FERRAJOLI, Luigi. Direito e Razão: Teoria do garantismo penal. $4^{\mathrm{a}}$ Ed. São Paulo: Revista dos Tribunais, 2014.

GOYARD-FABRE, Simone. Os princípios filosóficos do direito político moderno. São Paulo: Martins Fontes, 2002.

HASSEMER, Winfried. Por qué no debe suprimirse el Derecho Penal. México: Instituto Nacional de Ciencias Penales, 2003.

JAKOBS, Günther; MELIÁ, Manuel Cancio. Direito penal do inimigo, noções e críticas. Tradução de André Luis Callegari e Nobreu José Giancomolli. 2 Ed. Cidade: Editora Livraria do Advogado. 2007.

LUISI, Luiz Benito Viggiano. Os Princípios Constitucionais Penais. Porto Alegre: Sérgio Antônio Fabris, 2003.

REALE JÚNIOR, Miguel. Novos rumos do sistema criminal. Rio de Janeiro: Editora Forense, 1983.

SICA, Leonardo. Direito penal de emergência e alternativas a prisão. São Paulo: Editora Revista dos Tribunais, 2002.

SILVA FILHO, Edson Vieira da. A relativização das garantias penais ou: quem tem medo do garantismo penal? In: STRECK, Lenio Luiz (Org.). A discricionariedade nos sistemas jurídicos contemporâneos. Bahia: Editora Jus Podivm, 2017.

SILVA FILHO, Edson Vieira da. Minimalismo penal: uma reflexão crítica a partir de Eugenio Raúl Zaffaroni "Em busca das penas perdidas". In: SILVA FILHO, Edson Vieira da (Org.). $O$ Direito Penal e suas faces: Da Modernidade ao Neoconstitucionalismo - Volume 1: O Direito Penal visto em uma perspectiva minimalista. Curitiba: Editora CRV, 2012.

SILVA SÁNCHEZ, Jesús-María. A expansão do direito penal: aspectos da política criminal nas sociedades pós-industriais. Trad. Luiz Otávio de Oliveira Rocha. São Paulo: Revista dos Tribunais, 2013. 
SILVA, Marina Helena Vieira da. POSTERARO, Talita Piedade. Tolerância Zero. In: SILVA FILHO, Edson Vieira da (Org.). O Direito Penal e suas faces: Da modernidade ao Neoconstitucionalismo: Volume 2 - O Direito Penal visto de uma perspectiva maximalista. São Paulo: Lexia, 2013.

STRECK, Lenio Luiz. SANTOS JÚNIOR, Rosivaldo Toscano dos. Do Direito Penal do Inimigo ao Direito Penal do Amigo do Poder. Revista de Estudos Criminais 51, Doutrina Nacional. Out./Dez. 2013. Acesso em http://www.bdr.sintese.com/AnexosPDF/REC\%2051\%20-\%20doutrina\%20nacional.pdf.

VAZ, Paulo Afonso Brum. O sistema penal e o medo do crime: influência midiática, retirada do Estado Social, políticas criminais e expansionismo. Revista de Doutrina da $4^{a}$ Região, Porto Alegre, n.70, fev. 2016. Disponível em: https://revistadoutrina.trf4.jus.br/artigos/edicao070/PauloAfonso_Vaz.html.

WACQUANT, Loïc. Os excluídos da sociedade de consumo: toxicodependentes, psicopatas e sem-abrigo nas prisões americanas. Anál. Social, Lisboa, n. 185, P. 987-1003, 2007. Disponível em: http://www.scielo.mec.pt/scielo.php?script=sci_arttext\&pid=S0003$25732007000400002 \& \operatorname{lng}=$ en\&nrm=iso.

WERMUTH, Maiquel Ângelo Dezordi. Medo e Direito Penal: Reflexos da expansão punitiva na realidade brasileira. Porto Alegre: Livraria do Advogado. 2011.

ZAFFARONI, Eugenio Raúl. O inimigo no direito penal. Trad. Sérgio Lamarão. Rio de Janeiro: Revan. 2007.

Data de Submissão: 01/05/2020

Data de Aceite: 07/08/2020 